\title{
Occupational Contact Urticaria Caused by Airborne Methylhexahydrophthalic Anhydride
}

\author{
Kozo YOKOTA*, Yasushi JOHYAMA, Hiroshi MIYAUE, \\ Naomi MATSUMOTO and Kyohei YAMAGUCHI
}

Matsushita Science Center of Industrial Hygiene, 7-6 Tonoshima-cho, Kadoma, Osaka 571-0045, Japan

Received February 16, 2001 and accepted June 22, 2001

\begin{abstract}
Acid anhydrides are low-molecular weight chemicals known to cause respiratory irritancy and allergy. Skin allergy has on rare occasions been reported. A total of 3 subjects with occupational exposure to methylhexahydrophthalic anhydride (MHHPA) and hexahydrophthalic anhydride (HHPA) from an epoxy resin system were studied to evaluate the nature of their reported skin and nose complaints (work-related anamnesis, specific IgE, contact urticaria examinations, and ambient monitoring). Using a Pharmacia CAP system with a HHPA human serum albumin conjugate, specific IgE antibody was detected in serum from $1(33.3 \%)$ out of the 3 workers. One unsensitized worker displayed nasal pain and rhinorrhea only when loading liquid epoxy resins into the pouring-machine (2.2 $\mathrm{mg} \mathrm{MHHPA} / \mathrm{m}^{3}$ and $1.2 \mathrm{mg} \mathrm{HHPA} / \mathrm{m}^{3}$ ), probably being an irritant reaction. Two workers had work-related symptoms at relatively low levels of exposure (geometric mean 32-103 $\mu \mathrm{g}$ MHHPA/m ${ }^{3}$ and 18-59 $\mu \mathrm{g} \mathrm{HHPA} / \mathrm{m}^{3}$ ); one complained of only rhinitis, and the other was sensitized against HHPA and displayed both rhinitis and contact urticaria (the face and neck). The worker's skin symptoms were evidently due to airborne contact, since she had not had any skin contact with liquid epoxy resin or mixtures of MHHPA and HHPA. These urticaria symptoms were confirmed by a 20-min closed patch test for MHHPA, but not by that for HHPA. The causative agent was considered to be MHHPA, although the specific IgE determination to MHHPA was not performed.
\end{abstract}

Key words: Occupational, Acid anhydride, Hexahydrophthalic anhydride, Methylhexahydrophthalic anhydride, Contact urticaria, Rhinitis

\section{Introduction}

Acid anhydrides are widely used in the production of alkyd and polyester resins and as curing agents for epoxy resins. Adverse health effects of occupational exposure to several anhydrides have earlier been described, including phthalic anhydride (PA), tetrachlorophthalic anhydride, trimellitic anhydride, maleic anhydride (MA), himic anhydride, and hexahydrophthalic anhydride (HHPA) $)^{1}$. These have irritating effects on mucous membranes and sensitizing properties, causing symptoms from the eyes and airways. On the other hand, cases of contact urticaria from methylhexahydrophthalic anhydride (MHHPA), methyltetrahydrophthalic anhydride

*To whom correspondence should be addressed.
(MTHPA), HHPA or MA in the manufacture of electrical machines $^{2-4)}$, condensers ${ }^{5,6)}$, ski poles ${ }^{4)}$ and polyester resin ${ }^{7)}$, have been more recently reported. Allergic contact dermatitis from MHHPA has also been described ${ }^{4}$.

As stated above, acid anhydrides are well-known occupational respiratory allergens, but rarely cause skin allergy. In the present report, findings of workers in an electronics plant who developed separate rhinitis or rhinitis with simultaneous contact urticaria from exposure to MHHPA and HHPA (Fig. 1) are described.

\section{Subjects and Methods}

\section{Production and subjects}

The plant that was investigated manufactures integrated 
<smiles>O=C1OC(=O)c2ccccc21</smiles>

phthalic anhydride (PA)<smiles>O=C1OC(=O)C2CCCCC12</smiles>

hexahydrophthalic anhydride (HHPA)<smiles>CC1CCC2C(=O)OC(=O)C2C1</smiles>

methylhexahydroph thalic anhydride (MHLHPA)<smiles>CC1=CCC2C(=O)OC(=O)C2C1</smiles>

methyltetrahydroph thalic anhydride (MTHFPA)

Fig. 1 Molecular structure of acid anhydride hardeners. circuits (ICs) for electric appliances. In the final process, which consists of two workplaces connected by a door, the ICs are encapsulated in epoxy resins containing a mixture of MHHPA and HHPA as a hardener. The encapsulation process is performed using uncured, premixed epoxy resins in pouring machines and in curing ovens (temperature $100^{\circ} \mathrm{C}$ ). The process allows anhydride vapor to escape into the environment, where it can be inhaled. After curing and cooling, the appearance of the ICs is examined in the neighboring workplace (including inspecting lines). It was visually demonstrated by smoke tubes that air currents from the encapsulation process did not flow to the neighboring workplace. About $190 \mathrm{~kg}$ of the epoxy resins were used in a month. PA was never used in this plant.

All of the subjects $(n=6)$ in the second group of the IC manufacture section were studied by questionnaire and immunologic investigations in May 2000. Three of these 6 workers worked with MHHPA and HHPA in the encapsulation process, and the other three worked in the neighboring workplace. Informed consent was obtained from each study participant.

\section{Medical examination}

The subjects completed a questionnaire about symptoms (from the eyes, nose, lower respiratory tract, and skin) and their relation to work, atopic history, smoking status, duration of employment, and occupational history. After that, a physical examination was performed by a physician (KY), and venous blood samples were collected for serologic investigations. Rhinitis, conjunctivitis, asthma or urticaria in the workplace more than twice a week, with no complaints at weekends or during holidays, were evaluated as indicating work-related symptoms.

\section{Antibody determinations}

Serum samples were stored frozen at $-20^{\circ} \mathrm{C}$. On the day of measurement, the samples were thawed at room temperature before use.

Atopy: The Pharmacia CAP system (Pharmacia, Uppsala, Sweden) was used according to the manufacturer's instructions to measure specific IgE to Japanese cedar, house dust, and house dust mite. Diagnosis of atopy was based on positive specific IgE to at least one of the three allergens tested.

Total and specific IgE determinations: Immunocaps with a human serum albumin (HSA) conjugate of phthalic anhydride (PA) were commercially available, while those with a HSA conjugate of MHHPA and of HHPA were not (Pharmacia). However, immunocaps with the HSA conjugate 
Table 1. Exposure levels $\left(\mu \mathrm{g} / \mathrm{m}^{3}\right)$ of methylhexahydrophthalic anhydride (MHHPA) and hexahydrophthalic anhydride (HHPA) in different parts of the plant

\begin{tabular}{|c|c|c|c|c|c|c|}
\hline & \multicolumn{3}{|c|}{1999} & \multicolumn{3}{|c|}{2000} \\
\hline & $\mathrm{N}$ & GM & GSD & $\mathrm{N}$ & GM & GSD \\
\hline \multicolumn{7}{|c|}{ Pouring department: } \\
\hline MHНPA & 1 & 103 & 1.37 & 1 & 34 & 2.02 \\
\hline HHPA & 1 & 59 & 1.35 & 1 & 18 & 2.26 \\
\hline \multicolumn{7}{|c|}{ Hardening department: } \\
\hline MHHPA & 1 & 92 & 1.50 & 1 & 32 & 1.71 \\
\hline HHPA & 1 & 51 & 1.53 & 1 & 20 & 1.70 \\
\hline
\end{tabular}

$\mathrm{N}$ : number of measurements; GM: geometric mean; GSD: geometric SD.

of HHPA were provided via the special laboratory service by Pharmacia Diagnostics. PA- and HHPA-specific IgE levels were measured by the CAP system, and specific IgE values of $>0.35 \mathrm{UA} / \mathrm{ml}$ were considered positive. Total IgE levels were also measured by the CAP system.

\section{Test performed to detect contact urticaria}

A 20-min closed patch test was performed using Finn Chambers $^{\circledR}$. For the tests, MHHPA (liquid) and HHPA (crystalline solids) were purchased from Tokyo Kasei Kogyo Co. Ltd. (Tokyo, Japan) and Wako Pure Chemical Ind. (Osaka, Japan), respectively. The test substances were undiluted and applied on the antecubital area of the arms. The occlusion time was $20 \mathrm{~min}$. The tests were read $10 \mathrm{~min}$ and $40 \mathrm{~min}$ after removal. The 20 -min closed patch tests with the undiluted acid anhydrides were also performed on 5 control persons.

\section{Air sampling and analysis}

The measurement of MHHPA and HHPA in the air has been made every six months since October 1999. Air samples were collected on silica-gel tubes (Komyo Rikagaku Kogyo, Ltd., Kanagawa, Japan) by personal sampling in the breathing zone of the workers and by area sampling with batteryoperated pumps. The sampling rate was $1 \mathrm{l} / \mathrm{min}$, and stationary air sampling was carried out at five or six representative points in each workplace. The sampled MHHPA and HHPA were analyzed by gas chromatography with electron-capture detection after derivatization, as previously described ${ }^{8}$. The detection limit for the two acid anhydrides was $1.0 \mu \mathrm{g} / \mathrm{m}^{3}$ in a $20-1$ air sample.

\section{Results and Case Reports}

Results of MHHPA and HHPA exposure data are listed in Table 1. The geometric mean concentrations of MHHPA and HHPA in the pouring department in 1999 were 103 and $59 \mu \mathrm{g} / \mathrm{m}^{3}$, respectively, and the corresponding values of MHHPA and HHPA in 2000 were 34 and $18 \mu \mathrm{g} / \mathrm{m}^{3}$, respectively; the geometric mean concentrations measured were very similar in the two departments (the pouring department and the hardening department). The different concentrations were governed by differences in the production levels. MHHPA composed about $64 \%$ of the anhydride exposure. MHHPA and HHPA were not detected in the workplace next to the encapsulation process (analytical detection limit $\left.1.0 \mu \mathrm{g} / \mathrm{m}^{3}\right)$.

The main characteristics and test results of the three workers with occupational exposure to MHHPA and HHPA are summarized in Table 2. For the reason stated, the specific IgE determination to MHHPA could not be performed. Three other workers (age 29-36; one female) from the neighboring workplace had relatively low levels of total $\mathrm{IgE}$ (median 51 and range 43-130 IU $/ \mathrm{ml}$ ), negative specific $\mathrm{IgE}$ determinations to PA and HHPA, and displayed no workrelated symptoms. Their mean employment time was 13.0 (range 11.0-14.0) years. There were $2(66.7 \%)$ smokers and $3(100 \%)$ atopics among them.

\section{Worker 1}

Worker 1 had been a pouring-machine operator since 1989. His job was to load the epoxy resin-containing MHHPA and HHPA into the pouring-machine, to add the epoxy resin to base products because of a lack of the resin, and to let the air out of the uncured products. The epoxy resin was hardened in ovens. He experienced high exposures to MHHPA and HHPA (120-655 and 62-401 $\left.\mu \mathrm{g} / \mathrm{m}^{3}\right)$ during different direct epoxy resin handling operations, but was not sensitized. Highest exposures to MHHPA and HHPA (2.2 and $1.2 \mathrm{mg} /$ $\mathrm{m}^{3}$ ) occurred when loading the epoxy resin. At that time he developed nasal pain and rhinorrhea due to mucosal irritation which soon disappeared. 
Table 2. Characteristics and test results of three workers with current exposure to methylhexahydrophthalic anhydride (MHHPA) and hexahydrophthalic anhydride (HHPA)

\begin{tabular}{llll}
\hline & Worker 1 & Worker 2 & Worker 3 \\
\hline Characteristics & & & \\
Age (years) & 29 & 29 & 29 \\
Gender & Male & Male & Female \\
Smoking & Smoker & Smoker & Nonsmoker \\
Atopic status & Atopic & Atopic & Atopic \\
Total IgE (IU/ml) & 85 & 66 & 110 \\
Work & Electrical & Inspection, & Inspection, repair \\
& insulating, repair & electrical insulating & \\
Duration of employment (years) & 11.0 & 11.0 & 11.0 \\
Work-related symptoms & Nasal irritation & Rhinitis & Urticaria, rhinitis \\
Specific IgE determinations (UA/ml) & & & \\
PA & $<0.35$ & $<0.35$ & 5.61 \\
MHHPA & Not done & Not done & Not done \\
HHPA & $<0.35$ & $<0.35$ & 9.01 \\
Min closed patch tests & & & \\
MHHPA & Not done & Negative & Positive \\
HHPA & Not done & Negative & Negative \\
\hline
\end{tabular}

${ }^{\mathrm{a}}<0.35 \mathrm{UA} / \mathrm{ml}=$ negative.

\section{Worker 2}

A 29-year-old man, hired in 1989, worked in inspecting lines and, especially when worker 1 was very busy (about 10 days a month), assisted him. Since 1993 the man was a pouring-machine sub-operator and worked most of the time in the pouring department. The exposure levels in the two workers (workers 1 and 2) were very similar. In 1998 he began to develop severe rhinitis and cough, which worsened during the work shifts. He worked without suitable respiratory protective equipment until he started to develop the work-related symptoms. Away from the encapsulation process he was symptom-free.

The specific IgE determinations to two anhydrides (PA and HHPA) were negative. In this case, however, clinically relevant sensitization can be assumed, although the specific IgE determination to MHHPA could not be performed. The diagnosis of probable occupational rhinitis was based on work-related anamnestic data and the disappearance of nasal symptoms during a period of nonexposure.

\section{Worker 3}

A 29-year-old woman has served as an inspector since 1989. The woman is atopic and has a history of asthma. She never handled liquid epoxy resin or hardeners as such, but she had intermittent, short-time exposure (30-60 min) while repairing defective products several times a month in the pouring department. In 1997 she developed rhinitis and urticaria symptoms (redness and itchy wheals) on her face and neck during the job. The skin symptoms disappeared 2 to $3 \mathrm{~h}$ after she left the job. From May 1999 she worked in the pouring department, with daily short-time exposure (30$60 \mathrm{~min}$ ). Several months later, she experienced the first urticaria symptoms over her entire body, including her face, after about $3 \mathrm{~h}$ of exposure.

The specific IgE determinations to PA $(5.61 \mathrm{UA} / \mathrm{ml})$ and HHPA (9.01 UA/ml) were elevated. The sensitization to PA possibly represents cross-reactivity to HHPA and/or MHHPA. The 20-min closed patch test with MHHPA was positive (small urticas on test area), showing a strong urticarial reaction after a further $30 \mathrm{~min}$, but with HHPA it was negative. Tests with the undiluted hardeners in 5 control subjects (including worker 2) were all negative. From her personal history of atopy and provocation tests, it was concluded that she had airborne contact urticaria from MHHPA, and a decision was made to remove her from exposure. Based on the work-related anamnestic data and positive specific IgE determinations, occupational allergic rhinitis was also diagnosed.

\section{Discussion}

MHHPA and HHPA have been reported to induce IgEmediated respiratory allergy, including asthma ${ }^{9-13)}$. Safe use demands control of the level of exposure causing allergic 
diseases in the workshop. In spite of the fact that MHHPA or HHPA has been used for decades in the industry, no occupational exposure limits (OELs) have been established for the two acid anhydrides in air. For PA, which is a similar compound, there is a standard of $2 \mathrm{mg} / \mathrm{m}^{3}$ (OEL-Ceiling) ${ }^{14}$. A total of 3 subjects had been usually exposed to a level of less than one-tenth of this OEL (Table 1), except direct handling of uncured epoxy resins, since no major changes in the production process or ventilation systems occurred since 1989. Two of the subjects complained of work-related allergic symptoms; one displayed only rhinitis, and the other was sensitized against HHPA and showed both rhinitis and contact urticaria. On the other hand, no subject had yet developed symptoms suggestive of asthma. Adverse responses occur in the exposed workers even at air levels below $2 \mathrm{mg} / \mathrm{m}^{3}$; accordingly, exposures to mixtures of MHHPA and HHPA should be kept as low as possible below this value.

Nowadays, skin or mucous membrane irritating levels of anhydrides in the air of workplaces are uncommon, due to adequate industrial hygienic measures. However, amounts reaching $2 \mathrm{mg} / \mathrm{m}^{3}$ MHHPA and $1 \mathrm{mg} / \mathrm{m}^{3}$ HHPA could be measured when loading liquid epoxy resin into the pouringmachine, causing work-related irritation of the upper airways. Automatic loading in an enclosed system is required for this activity. It is of interest that worker 1 showed no signs of $\operatorname{IgE}$ sensitization, although short-time peak exposures have a great impact on the production of IgE antibodies ${ }^{15}$. Very little is known about the underlying mechanism. Recent studies have shown that human leukocyte antigen (HLA) complex products or genes represent either a risk or a protective factor in the development of specific IgE to acid anhydrides ${ }^{16,17)}$. Thus, this phenomenon might be partly relevant to MHC II haplotype. Further extensive studies are required to consider this issue.

Workers 2 and 3 developed significant rhinitis. Although occupational rhinitis is not considered to be as serious as asthma, it can be troublesome for symptomatic workers, since it disturbs their activity during work and leads to a reduction in their quality of life ${ }^{18)}$. Concomitantly worker 3 contracted urticaria symptoms on uncovered skin (the face and neck), which were verified by the 20-min closed patch test with undiluted MHHPA. She had not had any skin contact with liquid epoxy resin or mixtures of MHHPA and HHPA. Thus, it is thought that exposure to both the respiratory tract and the skin resulted in a rhinitis reaction and an immediate urticarial reaction. As shown in Table 1, these effects seem to be associated with relatively low levels of exposure, suggesting that even a minimal amount of an anhydride may be enough to evoke the symptoms on exposed skin in a worker highly sensitive to the anhydride. Contact urticaria can be pathogenetically classified as nonimmunologic, immunologic, or of uncertain mechanism of action. In immunologic cases, these patients frequently have a personal or family history of atopy ${ }^{19}$. She also had a history of asthma.

According to the study of Jolanki et al. ${ }^{5,6)}$ on the nature of occupational dermatoses from epoxy resins, among 1622 cases of occupational skin diseases, there were 806 cases (49.7\%) of allergic contact dermatitis, 748 cases $(46.1 \%)$ of irritant contact dermatitis, 25 cases of contact urticaria, and 43 cases of other skin diseases. Only 2 of the 25 cases with allergic contact urticaria were due to an epoxy hardener, MHHPA. In our previous study ${ }^{20)}$, none of the 148 MTHPAexposed workers had had symptoms of work-related contact urticaria. Thus, occupational contact urticaria caused by anhydride hardeners is rare. However, more recent clinical observations indicate that anhydride hardeners induce immediate-type allergic skin reactions ${ }^{2-4,7}$. These findings seem to be overlooked by experts in occupational health, because type I allergic reactions often affect the respiratory tract and skin symptoms seem to subside quickly after cessation of exposure.

To our knowledge, this is the first report of a documented urticarial response to MHHPA based on a specific challenge test in a Japanese occupational population. Industrial physicians need to be aware of the whole adverse health effects of acid anhydrides and to pay more attention to immediate allergic skin symptoms when a physical examination is performed.

\section{References}

1) Venables KM (1989) Low molecular weight chemicals, hypersensitivity, and direct toxicity: the acid anhydrides. Br J Ind Med 46, 222-32.

2) Kanerva L, Alanko K, Jolanki R, Estlander T (1999) Airborne allergic contact urticaria from methylhexahydrophthalic anhydride and hexahydrophthalic anhydride. Contact Dermatitis 41, 339-41.

3) Tarvainen K, Jolanki R, Estlander T, Tupasela O, Pfäffli P, Kanerva L (1995) Immunologic contact urticaria due to airborne methylhexahydrophthalic and methyltetrahydrophthalic anhydrides. Contact Dermatitis 32, 204-9.

4) Kanerva L, Hyry H, Jolanki R, Hytonen M, Estlander $\mathrm{T}$ (1997) Delayed and immediate allergy caused by methyltetrahydrophthalic anhydride. Contact Dermatitis 
36, 34-8.

5) Jolanki R, Estlander T, Kanerva L (1987) Occupational contact dermatitis and contact urticaria caused by epoxy resins. Acta Derm Venereol 134 (suppl), 90-4.

6) Jolanki R, Kanerva L, Estlander T, Tarvinen K, Keskinen H, Henricks-Eckerman M-L (1990) Occupational dermatoses from epoxy resin compounds. Contact Dermatitis 23, 172-83.

7) Kanerva L, Alanko K (2000) Occupational allergic contact urticaria from maleic anhydride. Contact Dermatitis 42, 170-1.

8) Johyama Y, Yokota K, Takeshita T, Morimoto K (1999) Determination of methyltetrahydrophthalic anhydride in air using gas chromatography with electon-capture detection. Ind Health 37, 364-8.

9) Chee C, Lee H, Cheong T, Wang Y, Poh S (1991) Occupational asthma due to hexahydrophthalic anhydride: a case report. Br J Ind Med 48, 643-5.

10) Moller D, Gallagher J, Bernstein D, Wilcox T, Burroughs H, Bernstein (1985) Detection of IgEmediated respiratory sensitization in workers exposed to hexahydrophthalic anhydride. J Allergy Clin Immunol 75, 663-72.

11) Nielsen J, Welinder H, Ottosson H, Bensryd I, Venge P, Skerfving S (1994) Nasal challenge shows pathogenetic relevance of specific IgE serum antibodies for nasal symptoms caused by hexahydrophthalic anhydride. Clin Exp Allergy 24, 440-9.

12) Grammer L, Shaughnessy M, Lowenthal M, Yamold P (1994) Risk factors for immunologically mediated respiratory disease from hexahydrophthalic anhydride. J Occup Med 36, 642-6.
13) Keskinen H, Nordman H, Tupasela O, Vaheri E, Pfäffli P, Sarjanen M (1988) Methylhexahydrophthalic anhydride induced asthma and rhinitis. N Engl Reg All Proc 4, 397.

14) The Japan Society for Occupational Health (JSOH) (1999) Recommendation of Occupational Exposure Limits (1999-2000). J Occup Health 41, 191-206.

15) Welinder $\mathrm{H}$, Jonsson $B$, Nielsen J, Ottosson H, Gustavsson C (1994) Exposure-response relationships in the formation of specific antibodies to hexahydrophthalic anhydride in exposed workers. Scand J Work Environ Health 20, 459-65.

16) Young R, Barker R, Pile K, Cookson W, Newman Taylor AJ (1995) The association of HLA-DR3 with specific IgE to inhaled acid anhydride. Am J Respir Crit Care Med 151, 219-21.

17) Nielsen J, Johnson U, Welinder H, Bensryd I, Rylander L, Skerfving S (1996) HLA and immunenonresponsiveness in workers exposed to organic acid anhydrides. J Occup Environ Med 38, 1087-90.

18) Bousquet J, Bullinger M, Fayol C, Marquis P, Valentin B, Burtin B (1994) Assessment of quality of life in patients with perennial allergic rhinitis with the French version of the SF-36 health status questionnaire. J Allergy Clin Immunol 94, 182-8.

19) Fumagalli M, Gibelli E (1992) Occupational contact urticaria. Clin Dermatol 10, 205-11.

20) Yokota K, Yamaguchi K, Takesita T, Morimoto K (1998) The significance of specific IgG4 antibodies to methyltetrahydrophthalic anhydride in occupationally exposed subjects. Clin Exp Allergy 28, 694-701. 